\title{
Strategi Pengembangan UKM Gethuk Pisang Guna Melestarikan Makanan Tradisional
}

\author{
Wahyu Eko Cahyono ${ }^{1}$, Dedy Kunhadi ${ }^{2}$ \\ ${ }^{1,2}$ Teknik Industri Universitas WR. Supratman Surabaya \\ Jalan Arief Rachman Hakim No. 14 Surabaya \\ 1*wcrajendra5@gmail.com \\ ${ }^{2}$ kunhadi.unipra76@gmail.com
}

Dikirimkan: 02, 2020. Diterima: 03, 2020. Dipublikasikan: 03, 2020.

\begin{abstract}
Small and medium enterprises (SMEs) are business sectors that play an important role as a backbone of a nation or region"s economics. Most problems faced by small and medium enterprises (SMEs) are capital, management and production process. This study aims to give strategic proposals in expanding small and medium enterprises of gethuk pisang for conserving traditional food. The methods used in this research are internal factor evaluation (IFE), external factor evaluation (EFE), and strengths- weaknesses opportunities - threats (SWOT), so internal factors and external factors that faced by the small and medium enterprises can be identified. Based on SWOT analysis, some analysis strategy can be used to expand the small and medium enterprises of gethuk pisang. Result showed the small and medium enterprises of gethuk pisang were in first quadrant at SWOT cartesian diagram, meant the right strategies were strengths opportunities (SO) or Growth strategy. The strategies that will be used are local government holds traditional food festival, upgrade the quality of the product and use on-line marketing technology. In conclusion, the sales of gethuk pisang products from small and medium enterprises can increase and correlate with income increase, so small and medium enterprises (SMEs) of gethuk pisang can have competitiveness and grow.
\end{abstract}

Keywords-Strategy, Gethuk pisang, IFE, EFE, SWOT.

\begin{abstract}
Abstrak - Usaha kecil dan menengah (UKM) merupakan suatu sektor usaha yang memiliki peran penting sebagai tulang punggung perekonomian suatu negara atau daerah. Sebagian besar permasalahan-permasalahan yang dihadapi UKM adalah permodalan, manajemen, dan proses produksi. Penelitian ini bertujuan untuk memberikan usulan strategi dalam mengembangkan UKM gethuk pisang dalam melestarikan makanan tradisional. Metode yang digunakan dalam penelitian ini adalah Internal Factor Evaluation (IFE), External Factor Evaluation (EFE), dan Strengths-Weaknesses - Opportunities-Threats (SWOT), sehingga dapat diidentifikasi faktor-faktor internal yang dimiliki dan faktor-faktor eksternal yang dihadapi oleh UKM. Berdasarkan analisa SWOT, maka akan diperoleh beberapa alternatif strategi yang dapat digunakan dalam mengembangkan UKM gethuk pisang. Hasil penelitian menunjukkan bahwa UKM gethuk pisang berada di kuadran I pada diagram kartesius SWOT, yang berarti strategi yang tepat digunakan adalah strategi Strengths Opportunities (SO) atau strategi Growth. Strategi-strategi yang akan digunakan adalah: Pemerintah Daerah mengadakan festival makanan tradisional, mutu produk lebih ditingkatkan, dan memanfaatkan teknologi media pemasaran on-line. Dengan demikian, produk UKM gethuk pisang dapat terjadi peningkatan penjualan dan berkorelasi dengan peningkatan pendapatan, sehingga UKM gethuk pisang memiliki daya saing dan dapat berkembang.
\end{abstract}

Kata kunci - Strategi, Gethuk Pisang, IFE, EFE, SWOT

\section{Pendahuluan}

Usaha Kecil dan Menengah (UKM) memiliki peran strategis dengan memberikan kontribusi yang sangat besar bagi pembangunan dan perekonomian suatu negara maupun daerah. Peran strategis tersebut, antara lain: 1) Menyerap tenaga kerja; 2) Penghasil barang dan jasa pada tingkat harga yang terjangkau bagi kebutuhan rakyat banyak yang berpenghasilan rendah; dan
3) Penghasil devisa negara yang potensial, karena keberhasilannya dalam memproduksi komoditi non migas [1]. Hal tersebut mendorong pemerintah pusat maupun daerah terus berupaya terus menerus melakukan pelatihan dan pembinaan secara berkelanjutan dalam mengembangkan sektor UKM.

Perhatian pemerintah terhadap perkembangan usaha kecil dan menengah (UKM) sangat besar melalui program-program yang dilaksanakan oleh 
Kementerian koperasi dan usaha kecil menengah. Meskipun kepedulian pemerintah terhadap UKM sangat besar untuk menjadikan UKM berhasil dan berkembang, bukan berarti tanpa adanya kendala atau permasalahan.

UKM Gethuk pisang merupakan salah satu usaha makanan tradisional khas Kota Kediri yang terbuat dari bahan dasar pisang. Gethuk pisang berbeda dengan gethuk yang terbuat dari singkong atau ubi. Gethuk pisang menggunakan pisang jenis raja nangka, sehingga memiliki cita rasa yang khas. Selain itu juga dibungkus dengan daun pisang, sehingga menghasilkan aroma yang khas, dan gethuk pisang cuman bisa bertahan 2 hari pada kondisi normal.

Permasalahan yang dihadapi UKM adalah: 1) Modal, UKM belum mendapatkan akses atau pembiayaan perbankan sebesar $60-70 \%$; 2) Sumber Daya Manusia, peralatan masih konvensional dan belum menerapkan quality control terhadap produk, pemasaran produk masih konvensional yaitu mouth to mouth marketing; 3 ) Hukum, sebagian besar UKM masih berbadan hukum perorangan; dan 4) Akuntabilitas, Administrasi keuangan dan manajemen belum baik [2].

Selain itu, ada beberapa permasalahan yang dihadapi oleh UKM, antara lain: 1) Kurangnya inovasi produk; 2) Kapasitas produksi terbatas; 3) Modal; 4) Keterbatasan teknologi proses produksi; 5) Kualitas sumber daya manusia; 6) Pemasaran; 7) Kurangnya kontribusi pihak eksternal; dan 8) Kebijakan pemerintah [3].

Pemberdayaan UKM ditengah arus persaingan global perlu dipikirkan lebih lanjut, agar mampu bertahan dan bersaing terhadap produk-produk asing yang membanjiri sentrasentra industri. Oleh karena itu, perlu menciptakan iklim investasi domestik yang kondusif dalam upaya penguatan pasar dalam negeri [4].

Persaingan produk semakin kompetitif yang dilakukan antar pelaku UKM maupun industri besar, baik ditinjau dari segi inovasi produk, kualitas produk, maupun distribusi produk. Para pelaku usaha harus mampu menyajikan produk yang lebih unggul dibandingkan produk lainnya dalam menarik minat konsumen [5].

Potensi sumber daya alam di suatu daerah bisa dipilih menjadi produk unggulan terpilih di daerah tersebut, dengan menggunakan beberapa kriteria diantaranya sumber daya alam yang melimpah, kesiapan pemerintah, dan keunikan dari produk yang akan dihasilkan [6]. Menurut [7] konsep pengembangan inovasi di desa harus ada keterlibatan pihak perguruan tinggi dengan desa. Perguruan tinggi berperan sebagai pembina untuk kemajuan desa, dan sebagai fasilitator untuk pihak lain yang dibutuhkan. Beberapa kriteria dalam pengembangan potensi desa yaitu pemodalan, keterseiaan bahan baku, inovasi produk, kemasan yang menarik, promosi, sistem penjualan, dan manajemen usaha.

Strategi yang akan menjadi dasar keunggulan kompetitif secara terus-menerus bagi perusahaan dengan mengeksplorasi sumber keunggulan kompetitif untuk masa akan datang dan mengeksploitasi inovasi untuk saat ini [8]. Usaha kecil membentuk keunggulan kompetitif dengan mengembangkan alur kreativitas dan inovasi yang konsisten yang melebihi pesaing [9]. Faktor-faktor yang menentukan keunggulan bersaing, antara lain: inovasi produk, kreativitas produk, dan kualitas produk [10]. Sedangkan keunggulan bersaing dapat dipengaruhi oleh faktor orientasi kewirausahaan, inovasi produk, dan dukungan partner [11].

\section{METOdOLOGi PENELITIAN}

Penelitian ini merupakan penelitian kualitatif, yaitu untuk mengidentifikasi faktor-faktor internal dan eksternal dalam mengembangkan UKM gethuk pisang di Kota Kediri. Sedangkan metodologi penelitian dapat dilihat pada gambar 1 dibawah ini.

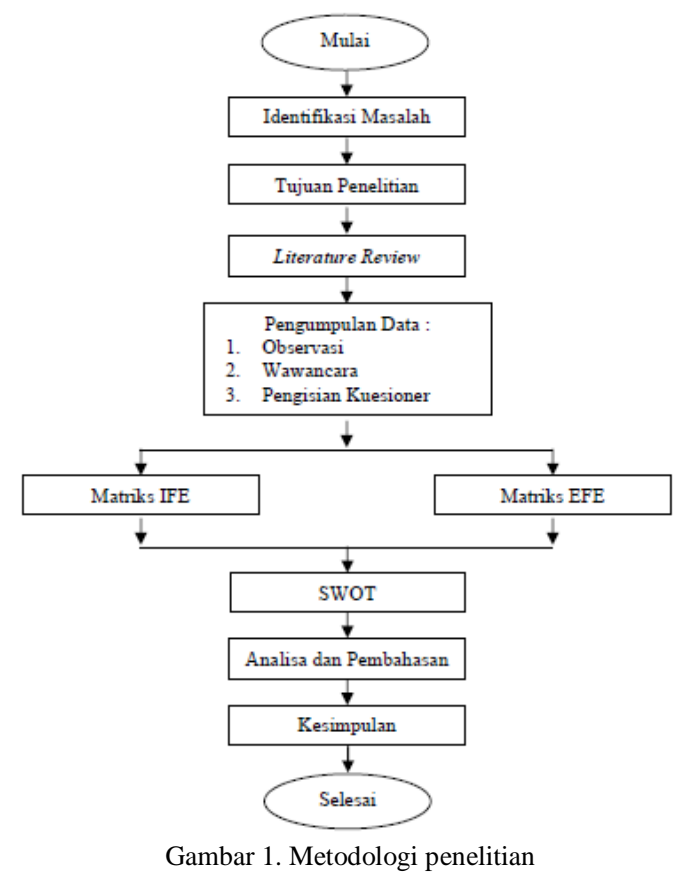

Berdasarkan gambar 1 dapat dijelaskan sebagai berikut:

1) Identifikasi Permasalahan

Dengan dibukanya pasar bebas, maka persaingan usaha semakin ketat, baik antar UKM makanan tradisional yang sejenis 
maupun produk makanan lainnya. UKM makanan tradisonal gethuk pisang dapat bertahan dan bersaing, tergantung strategi yang akan digunakan dalam mengembangkan UKM gethuk pisang tersebut.

2) Tujuan Penelitian

Tujuan dari penelitian ini adalah sebagai berikut:

a. Mengidentifikasi faktor-faktor internal dalam mengembangkan UKM gethuk pisang di Kota Kediri.

b. Mengidentifikasi faktor-faktor eksternal dalam mengembangkan UKM gethuk pisang di Kota Kediri.

c. Memberikan usulan strategi yang tepat dalam mengembangkan UKM gethuk pisang di Kota Kediri.

3) Literature Review

Literature review yang digunakan dalam penelitian ini didapatkan dari buku maupun artikel jurnal ilmiah, dan lain-lain yang masih berhubungan dengan penelitian ini. Metode yang digunakan dalam penelitian ini adalah matriks IFE, matriks EFE, dan SWOT.

a. Matriks Internal Factor Evaluation (IFE)

Matriks Internal Factor Evaluation (IFE) digunakan untuk mengidentifikasi dan mengevaluasi faktor-faktor kekuatan dan kelemahan (faktor internal) perusahaan yang dianggap penting [12].

b. Matriks External Factor Evaluation (EFE)

Matriks External Factor Evaluation (EFE) digunakan untuk mengidentifikasi dan mengevaluasi faktor-faktor peluang dan ancaman (faktor eksternal) dalam perusahaan atau organisasi [13].

c. Strengths - Weaknesses - OpportunitiesThreats (SWOT)

Analisis SWOT digunakan untuk merumuskan atau memformulasikan berbagai kemungkinan alternatif strategi, yaitu Strategi Strengths Opportunities (SO), Strengths Threats (ST), Weaknesses Opportunities (WO), dan Weaknesses Threats (WT) [11].

4) Pengumpulan data

Dalam penelitian menggunakan 2 jenis data, yaitu data primer dan data sekunder. Dimana data primer diperoleh dari observasi, wawancara, dan kuesioner. Sedangkan data sekunder diperoleh dari referensi pendukung penelitian (artikel jurnal) maupun dokumentasi UKM gethuk pisang yang berada di Kota Kediri.

Observasi dalam penelitian ini dapat dijelaskan bahwa pengamatan yang dilakukan secara langsung di lapangan (UKM gethuk pisang) mulai dari bahan baku, proses produksi, produk jadi, kemasan, dan pemasaran.

Sedangkan wawancara dan kuesioner ini dilakukan menggunakan pakar yang memiliki kompeten sesuai permasalahan dalam penelitian ini dengan menggunakan metode delphi. Metode delphi adalah suatu metode yang digunakan dalam pengambilan keputusan dengan melibatkan beberapa pakar yang memiliki kompeten dan identitas pakar disembunyikan serta tidak dipertemukan secara langsung dengan tujuan meminimalkan pendapat yang bias dan menghindari adanya dominasi pakar lain [14].

5) Analisa dan Pembahasan

Analisa yang digunakan dalam penelitian ini adalah Matriks Internal Factor Evaluation (IFE), Matriks External Factor Evaluation (EFE), dan Strengths-Weaknesses Opportunities-Threats (SWOT). Dengan menggunakan analisa tersebut diharapkan dapat memberikan usulan strategi yang tepat dalam mengembangkan UKM gethuk pisang guna melestarikan makanan tradisional.

6) Kesimpulan

Dari hasil analisa dan pembahasan, maka penelitian ini dapat ditarik suatu kesimpulan.

\section{HASIL PENELITIAN}

Berdasarkan hasil wawancara dan penyebaran kuesioner ke pakar yang berjumlah 3 orang dan memiliki kompeten sesuai permasalahan penelitian ini, maka diidentifikasi faktor-faktor internal dan eksternal yang dapat mempengaruhi pengembangan UKM gethuk pisang dalam melestarikan makanan tradisional.

Faktor-faktor internal dalam mengembangkan UKM gethuk pisang adalah:

1) Faktor kekuatan

a. Produk UKM merupakan makanan khas tradisional daerah

b. Produk tidak menggunakan bahan pengawet

c. Memiliki cita rasa khas

d. Harga produk relatif murah

2) Faktor kelemahan

a. Sebagian besar sumber daya manusia masih berpendidikan rendah

b. Permodalan terbatas

c. Peralatan produksi manual

d. Bahan baku musiman

Sedangkan faktor-faktor eksternal dalam mengembangkan UKM gethuk pisang adalah:

1) Faktor peluang

a. Jumlah penduduk semakin meningkat 


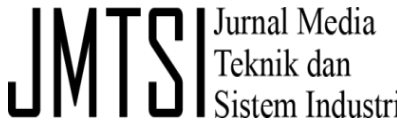

b. Potensi pasar masih terbuka lebar

c. Teknologi semakin berkembang

d. Perhatian dan kepedulian Pemerintah terhadap UKM

2) Faktor ancaman

a. Berbagai produk makanan baru bermunculan

b. Rendahnya minat pemilik UKM dalam mengembangkan usahanya

c. Fluktuasi ekonomi global

d. Harga BBM naik

Setelah diidentifikasi faktor-faktor internal dan eksternal, maka dilakukan evaluasi faktorfaktor tersebut dengan menggunakan matriks IFE dan matriks EFE, dimana hasilnya dapat dilihat pada lampiran 1 dan lampiran 2.

Berdasarkan lampiran 1 yang merupakan hasil dari matriks IFE dapat diketahui bahwa skor bobot untuk faktor kekuatan sebesar 2.59, dan faktor kelemahan memiliki skor bobot sebesar 0.50. Sedangkan total skor bobot untuk faktorfaktor internal sebesar 3.09, dimana total skor bobot tersebut diatas rata-rata sebesar 2.5 yang menunjukkan bahwa UKM gethuk pisang di Kota Kediri dapat memanfaatkan kekuatan yang dimiliki untuk mengatasi kelemahan yang ada.

Hasil dari matriks EFE yang dapat dilihat pada lampiran 2 dapat diketahui bahwa faktor peluang memiliki skor bobot sebesar 1.91, dan skor bobot untuk faktor ancaman sebesar 1.39. Sedangkan faktor-faktor eksternal memiliki total skor bobot diatas rata-rata 2.5, yaitu sebesar 3.30 yang menunjukkan bahwa UKM gethuk pisang dapat memanfaatkan peluang untuk menghindari ancaman yang ada.

Nilai skor bobot faktor kekuatan lebih besar dibandingkan faktor kelemahan dengan selisih sebesar (+) 2.09, dan faktor peluang lebih besar dibandingkan faktor ancaman dengan selisih total skor bobot sebesar (+) 0.52. Dari hasil identifikasi faktor-faktor tersebut maka dapat digambarkan ke dalam diagram kartesius SWOT.

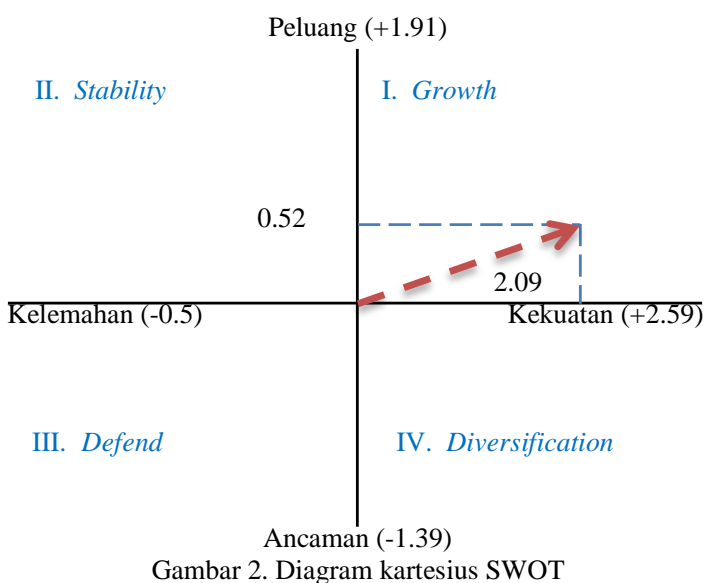

Berdasarkan diagram kartesius SWOT diatas, maka dapat dijelaskan bahwa UKM gethuk pisang di Kediri berada pada kuadran I yang berarti strategi yang tepat digunakan adalah strategi Strengths Opportunities (SO) atau strategi Growth. Strategi tersebut dengan memanfaatkan peluang sebesar-besarnya dengan kekuatan yang dimiliki UKM gethuk pisang.

\section{IV.PEMBAHASAN}

Berdasarkan hasil analisa SWOT pada lampiran 3, maka didapatkan beberapa alternatif strategi dalam mengembangkan UKM gethuk pisang dalam melestarikan makanan tradisional, yaitu:

1) Strategi Strengths Opportunities (SO)

a. Pemerintah daerah mengadakan festival makanan tradisional

Pemerintah daerah secara rutin mengadakan festival makanan tradisional dan menyiapkan kawasan khusus outlet makanan tradisonal, sehingga masyarakat yang belum paham makanan tradisional daerah dapat mengerti dan mencoba makanan tradisional daerah tersebut.

b. Mutu produk lebih ditingkatkan

UKM hendaknya selalu meningkatkan mutu produk secara terus menerus. Hal ini mengingat kondisi normal gethuk pisang hanya bisa bertahan sampai 2 hari, maka perlu diusahakan agar daya tahan produk dapat ditingkatkan lagi, tetapi tetap menjaga nilai kesehatan.

c. Memanfaatkan teknologi media pemasaran on-line

UKM memanfaatkan teknologi dalam memasarkan produk gethuk pisang secara on-line guna meningkatkan jumlah penjualan, seperti website, media sosial, gojek, grab, shopee, dan lain-lain.

2) Strategi Strengths Threats (ST)

a. Menjaga kualitas produk

Dengan berkembangnya teknologi, maka akan bermunculan berbagai macam produk baru. Hal yang terpenting dilakukan adalah menjaga kualitas produk makanan tradisional dengan menjaga bahan baku yang digunakan benar-benar pilihan dan tidak dikurangi komposisinya.

b. Meningkatkan jiwa wirausaha dalam melakukan inovasi produk

Kurangnya minat wirausaha, maka usaha tersebut akan berjalan stagnan. Oleh karena itu, Pemerintah atau pihak terkait lainnya, seperti akademisi dapat meningkatkan jiwa dan kesadaran 
wirausaha untuk maju dan berkembang. Wirausaha yang berkembang akan melakukan inovasi produk makanan tradisional yang berbeda dengan yang lainnya tanpa menghilangkan karakter bumbu makanan tradisional tersebut.

c. Menggunakan bahan baku lokal

Fluktuasi ekonomi global akan berdampak pada melemahnya nilai tukar mata uang domestik (rupiah). Nilai tukar mata uang akan memicu lemahnya daya beli, sehingga akan berdampak pada kapasitas produksi tidak maksimal. Selain itu usaha yang menggunakan bahan baku import akan terkena dampaknya juga. Oleh karena itu, usaha makanan tradisional yang menggunakan bahan baku lokal akan lebih bertahan dari fluktuasi ekonomi global tersebut.

d. Mengurangi marjin keuntungan

Naik turunnya harga BBM mengikuti harga minyak dunia. Apabila harga minyak dunia naik, maka harga BBM juga akan mengalami kenaikan, sehingga biaya produksi juga mengalami kenaikan. Guna mengatasi kenaikan biaya tersebut, maka UKM dapat mengurangi marjin keuntungan tanpa mengurangi kualitas bahan baku dan cita rasa yang khas dari produk tersebut.

3) Strategi Weaknesses Opportunities (WO)

a. Mengembangkan kualitas sumber daya manusia

Sebagian besar UKM memiliki sumber daya manusia yang berlatar belakang pendidikan yang rendah. Oleh karena itu, pemerintah memberikan bantuan berupa pelatihan-pelatihan dalam meningkatkan kompetensi sumber daya manusia, sehingga diharapkan dapat meningkatkan kualitas produk dan inovasi produk.

b. Pemerintah membantu dalam memberikan pinjaman modal melalui kredit usaha rakyat (KUR)

Sebagian besar permasalahan yang dihadapi oleh UKM adalah permodalan. Oleh karena itu, pemerintah memberikan fasilitas pinjaman berupa kredit usaha rakyat (KUR), sehingga UKM dapat meningkatkan jumlah produksinya, inovasi produk, dan memperluas usahanya agar dapat dikembangkan guna menangkap peluang pasar yang masih terbuka.

c. Pemerintah memberikan bantuan peralatan produksi

Sebagian besar UKM masih menggunakan peralatan manual, sehingga proses produksi belum efisien dan efektif.
Oleh karena itu, pemerintah melalui dinas koperasi dan UKM memberikan bantuan peralatan kepada UKM yang sudah terdaftar, bantuan tersebut dapat berupa peralatan produksi semi otomatis atau otomatis, supaya UKM dapat meningkatkan kapasitas produksinya.

d. Menciptakan atau membuat produk baru

Dengan teknologi semakin berkembang maka dapat menambah pengetahuan mengenai pembuatan produk dengan bahan baku lainnya, tetapi memiliki ciri khas yang berbeda serta unik dibandingkan UKM lainnya.

4) Strategi Weaknesses Threats (WT)

a. Bekerjasama dengan Perguruan Tinggi

Perguruan tinggi dengan UKM tarjalin link and match, dimana perguruan tinggi melakukan penelitian sehingga menghasilkan temuan-temuan baru dibidang ilmu pengetahuan dan inovasi serta diaplikasikan pada kegiatan pemberdayaan UKM dalam mengelola dan mengembangkan usahanya. Kolaborasi perguruan tinggi dan UKM dapat menyelesaikan permasalahan-permasalahan yang sedang dihadapi UKM, seperti: rendahnya kesadaran berwirausaha, kesulitan pemasaran, persaingan dengan munculnya produk-produk baru, pengadaan bahan baku yang terbatas, kurangnya keterampilan dan pengetahuan, peralatan proses produksi, dan terjadinya fluktuasi ekonomi global. Selain itu, perguruan tinggi bukan memberikan modal usaha, tetapi untuk membina kemampuan dan keterampilan UKM dalam menyusun suatu proposal pendanaan yang ditujukan ke lembaga-lembaga pemberi modal dan menghitung modal yang dibutuhkan. Dengan perguruan tinggi melakukan kegiatan pemberdayaan UKM, supaya UKM dapat menjadi motor penggerak ekonomi kerakyatan

b. Pemerintah berusaha mengontrol kenaikan harga BBM

Kenaikan harga BBM akan berdampak pada kenaikan harga bahan baku yang digunakan dalam proses produksi. Oleh karena itu, pemerintah berusaha 
mengontrol harga BBM agar stabil, supaya harga produk tetap stabil dipasaran.

\section{KESIMPULAN}

Berdasarkan hasil penelitian dan pembahasan diatas, maka dapat ditarik kesimpulan:

1) Faktor-faktor internal yang mempengaruhi pengembangan UKM gethuk pisang antara lain: a) Faktor kekuatan, meliputi: Produk UKM merupakan makanan khas tradisional daerah, Produk tidak menggunakan bahan pengawet, Memiliki cita rasa khas, dan Harga produk relatif murah; b) Faktor Kelemahan, meliputi: Sebagian besar sumber daya manusia masih berpendidikan rendah, Permodalan terbatas, Peralatan produksi manual, dan Bahan baku musiman.

2) Faktor-faktor eksternal yang mempengaruhi pengembangan UKM gethuk pisang antara lain: a) Faktor peluang, meliputi: Jumlah penduduk semakin meningkat, Potensi pasar masih terbuka lebar, Teknologi semakin berkembang, dan Perhatian dan kepedulian Pemerintah terhadap UKM; b) Faktor ancaman, meliputi: Berbagai produk makanan baru bermunculan, Rendahnya minat pemilik UKM dalam mengembangkan usahanya, Fluktuasi ekonomi global, dan Harga BBM naik

3) UKM gethuk pisang berdasarkan diagram kartesius SWOT berada di kuadran I. Hal tersebut menunjukkan strategi yang digunakan adalah strategi Strengths Opportunities (SO) atau strategi Growth yang meliputi antara lain: a) Pemerintah daerah mengadakan festival makanan tradisional, b) Mutu produk lebih ditingkatkan, dan c) Memanfaatkan teknologi media pemasaran on-line

\section{REFERENSI}

[1] Irawati, R. (2018). Pengaruh Pelatihan Dan Pembinaan Terhadap Pengembangan Usaha Kecil. Jurnal Ilmiah Bisnis dan Ekonomi Asia, 12(1), 74-84.

[2] Bank Indonesia. (2015). Profil bisnis usaha mikro, kecil dan menengah (UMKM). Jakarta: Lembaga Pengembangan Perbankan Indonesia.

[3] Hamid, E. S., \& Susilo, Y. (2011). Strategi pengembangan usaha mikro kecil dan menengah di

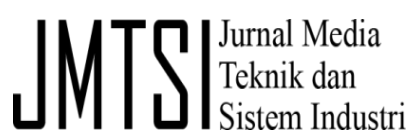

Provinsi Daerah Istimewa Yogyakarta. Jurnal Ekonomi Pembangunan, 12(1), 45-55.

[4] Sudaryanto, R., \& Wijayanti, R. R. (2013). Strategi pemberdayaan UMKM menghadapi pasar bebas Asean. Pusat Kebijakan Ekonomi Makro. Badan Kebijakan Fiskal. Kementerian Keuangan, Jakarta.

[5] Lestari, C., Lubis, N., \& Widayanto, W. (2015). Pengaruh Jaringan USAha, Inovasi Produk Dan Persaingan USAha Terhadap Perkembangan USAha Mikro, Kecil Dan Menengah (Studi Pada IKM Makanan Di Kecamatan Kuningan Kabupaten Kuningan Jawa Barat). Jurnal Ilmu Administrasi Bisnis, 4(2), 185-196.

[6] A. Sutoni, "Determination of regional main products with fuzzy logic approach in regional Sula Island of North Maluku Province," in 3rd International Conference on Digital Arts, Media and Technology, ICDAMT 2018, 2018, doi: 10.1109/ICDAMT.2018.8376488.

[7] A. Sutoni and I. Masrofah, "Konsep Pengembangan Inovasi Keripik Gadung, Dalam Pemberdayaan Masyarakat Di Desa Kutawaringin, Kecamatan Mande, Kabupaten Cianjur," IKRA-ITH Abdimas, vol. 1, no. 2, pp. 71-79, 2018.

[8] Ireland, D.W., dan Webb, J. 2006. Strategic Entrepreneurship: Creating Competitive Advantage Through Streams Of Innovation, Business Horizons. 50, pp.49-59.

[9] Metekohy, S. (2013). Pengaruh strategi resource-based dan orientasi kewirausahaan terhadap keunggulan bersaing usaha kecil dan usaha mikro (studi pada usaha jasa etnis Maluku). Jurnal Aplikasi Manajemen, 11(1), 12-20.

[10] Kurniasari, R. D, \& Utama, A. (2018). Pengaruh Inovasi Produk, Kreativitas Produk, Dan Kualitas Produk Terhadap Keunggulan Bersaing (Studi Kasus Pada Kerajinan Enceng Gondok "AKAR”. Jurnal Manajemen Bisnis Indonesia (JMBI), 7(5), 467-477.

[11] Puspasari, E. L., \& Rahardjo, S. T. (2017). Pengaruh Orientasi Kewirausahaan, Inovasi Produk, Dan Dukungan Partner Terhadap Keunggulan Bersaing (Studi Pada Industri Makanan Dan Minuman Skala Kecil Dan Menengah Di Kota Semarang). Diponegoro Journal of Management, 6(3), 225-232.

[12] Abdurrahim, M. F. H., Daryanto, A., \& Nurmalina, R. (2014). Strategi pengembangan balai penelitian bioteknologi perkebunan Indonesia. Jurnal Manajemen \& Agribisnis, 11(3), 199-208.

[13] Rosalina, E., \& Wirahadi Ahmad, A. (2016, October). Analisa Strategi Pengembangan Industri Makanan Tradisional Minangkabau Berbasis Pendekatan SWOT. In National Conference of Applied Engineering, Business and Information Technology, Politeknik Negeri Padang (pp. 96-100). ASCNI-Tech.

[14] Tambun, B. S., Jananuraga, I. G., Mahatmavidya, P. A., \& Soesanto, R. P. (2014). Perancangan Sistem Informasi Berbasis Geografis untuk Mendukung Keputusan Pemilihan Tempat Makan di Kawasan Pendidikan Telkom University dengan Menggunakan Metode Factor Rating dan Metode Delphi. 
LAMPIRAN 1. Matriks Internal Factor Evaluation (IFE)

\begin{tabular}{|c|c|c|c|c|c|}
\hline No & Faktor-Faktor Internal & Kode & Bobot & Rating & Skor Bobot \\
\hline \multicolumn{6}{|c|}{ Kekuatan (Strength) } \\
\hline 1 & $\begin{array}{l}\text { Produk UKM merupakan makanan khas } \\
\text { tradisional daerah }\end{array}$ & S1 & 0.20 & 4.0 & 0.80 \\
\hline 2 & Produk tidak menggunakan bahan pengawet & $\mathrm{S} 2$ & 0.17 & 3.7 & 0.63 \\
\hline 3 & Memiliki cita rasa khas & S3 & 0.16 & 3.3 & 0.53 \\
\hline 4 & Harga produk relatif murah & S4 & 0.17 & 3.7 & 0.63 \\
\hline \multicolumn{3}{|c|}{ Sub Total } & 0.70 & & 2.59 \\
\hline \multicolumn{6}{|c|}{ Kelemahan (Weakness) } \\
\hline 1 & $\begin{array}{l}\text { Sebagian besar sumber daya manusia masih } \\
\text { berpendidikan rendah }\end{array}$ & W1 & 0.10 & 2.0 & 0.20 \\
\hline 2 & Permodalan terbatas & W2 & 0.08 & 1.7 & 0.14 \\
\hline 3 & Peralatan produksi manual & W3 & 0.06 & 1.3 & 0.08 \\
\hline 4 & Bahan baku musiman & W4 & 0.06 & 1.3 & 0.08 \\
\hline \multicolumn{3}{|c|}{ Sub Total } & 0.30 & & 0.50 \\
\hline \multicolumn{3}{|c|}{ TOTAL } & 1.00 & & 3.09 \\
\hline
\end{tabular}

LAMPIRAN 2. Matriks External Factor Evaluation (EFE)

\begin{tabular}{|c|c|c|c|c|c|}
\hline No & Faktor-Faktor Eksternal & Kode & Bobot & Rating & Skor Bobot \\
\hline \multicolumn{6}{|c|}{ Peluang (Opportunity) } \\
\hline 1 & Jumlah penduduk semakin meningkat & $\mathrm{O} 1$ & 0.14 & 3.7 & 0.52 \\
\hline 2 & Potensi pasar masih terbuka lebar & $\mathrm{O} 2$ & 0.15 & 4.0 & 0.60 \\
\hline 3 & Teknologi semakin berkembang & $\mathrm{O} 3$ & 0.12 & 3.0 & 0.36 \\
\hline 4 & $\begin{array}{l}\text { Perhatian dan kepedulian Pemerintah } \\
\text { terhadap UKM }\end{array}$ & $\mathrm{O} 4$ & 0.13 & 3.3 & 0.43 \\
\hline \multicolumn{3}{|c|}{ Sub Total } & 0.54 & & 1.91 \\
\hline \multicolumn{6}{|c|}{ Ancaman(Threats) } \\
\hline 1 & $\begin{array}{l}\text { Berbagai produk makanan } \\
\text { bermunculan }\end{array}$ & T1 & 0.13 & 3.3 & 0.43 \\
\hline 2 & $\begin{array}{l}\text { Rendahnya minat pemilik UKM dalam } \\
\text { mengembangkan usahanya }\end{array}$ & $\mathrm{T} 2$ & 0.09 & 2.7 & 0.24 \\
\hline 3 & Fluktuasi ekonomi global & T3 & 0.12 & 3.0 & 0.36 \\
\hline 4 & Harga BBM naik & T4 & 0.12 & 3.0 & 0.36 \\
\hline \multicolumn{3}{|c|}{ Sub Total } & 0.46 & & 1.39 \\
\hline \multicolumn{3}{|c|}{ TOTAL } & $\mathbf{1 . 0 0}$ & & 3.30 \\
\hline
\end{tabular}


LAMPIRAN 3. Analisa Strengths-Weaknesses - Opportunities-Threats (SWOT)

\begin{tabular}{|c|c|c|}
\hline & STRENGTH & WEAKNESS \\
\hline EKSTERNAL & 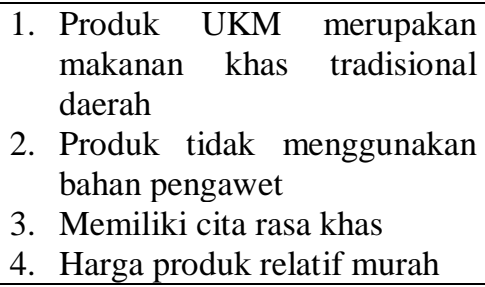 & $\begin{array}{l}\text { 1. Sebagian besar sumber daya } \\
\text { manusia masih berpendidikan } \\
\text { rendah } \\
\text { 2. Permodalan terbatas } \\
\text { 3. Peralatan produksi manual } \\
\text { 4. Bahan baku musiman }\end{array}$ \\
\hline OPPORTUNITY & Strategi SO & Strategi WO \\
\hline $\begin{array}{l}\text { 1. Jumlah penduduk semakin } \\
\text { meningkat } \\
\text { 2. Potensi pasar masih terbuka } \\
\text { lebar } \\
\text { 3. Teknologi } \\
\text { berkembang } \\
\text { 4. Perhatian dan kepedulian } \\
\text { Pemerintah terhadap UKM }\end{array}$ & $\begin{array}{l}\text { 1. Pemerintah daerah mengada- } \\
\text { kan festival makanan } \\
\text { tradisional } \\
\text { 2. Mutu produk lebih } \\
\text { ditingkatkan } \\
\text { 3. Memanfaatkan teknologi } \\
\text { media pemasaran on-line }\end{array}$ & $\begin{array}{l}\text { 1. Mengembangkan kualitas } \\
\text { sumber daya manusia } \\
\text { 2. Pemerintah membantu dalam } \\
\text { memberikan pinjaman modal } \\
\text { melalui KUR } \\
\text { 3. Pemerintah memberikan } \\
\text { bantuan peralatan produksi } \\
\text { 4. Menciptakan atau membuat } \\
\text { produk baru }\end{array}$ \\
\hline THREATS & Strategi ST & Strategi WT \\
\hline $\begin{array}{l}\text { 1. Berbagai produk makanan } \\
\text { baru bermunculan } \\
\text { 2. Rendahnya minat pemilik } \\
\text { UKM } \\
\text { mengembangkan usahanya } \\
\text { 3. Fluktuasi ekonomi global } \\
\text { 4. Harga BBM naik }\end{array}$ & $\begin{array}{l}\text { 1. Menjaga kualitas produk } \\
\text { 2. Meningkatkan jiwa wirausa- } \\
\text { ha dalam melakukan inovasi } \\
\text { produk } \\
\text { 3. Menggunakan bahan baku } \\
\text { lokal } \\
\text { 4. Mengurangi marjin keun- } \\
\text { tungan }\end{array}$ & $\begin{array}{l}\text { 1. Bekerjasama dengan perguruan } \\
\text { tinggi } \\
\text { 2. Pemerintah } \\
\text { mengontrol kenaikan harga } \\
\text { BBM }\end{array}$ \\
\hline
\end{tabular}

